OPEN ACCESS

Edited by:

Nicolas Oscar Soto-Cruz,

Durango Institute of

Technology, Mexico

Reviewed by:

S. K. Jadhav,

Pandit Ravishankar Shukla

University, India

Jorge Alejandro Santiago-Urbina,

Universidad Tecnológica de los Valles

Centrales de Oaxaca, Mexico

*Correspondence:

Alma G. Verdugo-Valdez

alma.verdugo@unicach.mx

tThese authors have contributed equally to this work and share first authorship

Specialty section:

This article was submitted to Sustainable Food Processing,

a section of the journal

Frontiers in Sustainable Food Systems

Received: 15 April 2021

Accepted: 26 July 2021

Published: 24 August 2021

Citation:

Ambrocio-Ríos JA, Orantes-García C,

Sánchez-Cortés MS and

Verdugo-Valdez AG (2021) Use of the

Coyol Palm (Acrocomia aculeata) for

the Production of "Taberna," a

Traditional Fermented Beverage in

México.

Front. Sustain. Food Syst. 5:695494. doi: 10.3389/fsufs.2021.695494

\section{Use of the Coyol Palm (Acrocomia aculeata) for the Production of "Taberna," a Traditional Fermented Beverage in México}

\author{
José A. Ambrocio-Ríos, Carolina Orantes-García ${ }^{\dagger}$, María S. Sánchez-Cortés ${ }^{\dagger}$ and \\ Alma G. Verdugo-Valdez*
}

Instituto de Ciencias Biológicas, Universidad de Ciencias y Artes de Chiapas, Tuxtla Gutiérrez, Mexico

Acrocomia aculeata is a palm, which is used for various purposes in different rural communities in southeastern Mexico; among which is the obtaining of a traditional fermented beverage called "taberna." The objective of this study was to know the management that taberna producers give to the coyol palm. The work was carried out between march and april 2016 in two communities in Chiapas. The information on palm management was obtained by applying semi-structured interviews to the families that make the beverage in each community, who narrated the process of using the palm; from its care in the field, to its court for the elaboration of a taberna and the uses and customs that revolve around this activity were described. With this work, it was possible to know the details of the elaboration of the beverage from a social and cultural perspective, which is surrounded by traditional knowledge, with great biocultural importance that gives identity not only to the communities that possess the resource, but also to the families that they take advantage of it. With this, it is expected to contribute to a management and conservation plan for the species, to guarantee the resource to the communities and preserve the biological and cultural diversity associated with this activity, given that the use of natural resources is ultimately a biocultural heritage that implies a relationship between natural resources, people, regions and local culture.

Keywords: taberna, palm, beverage, Acrocomia, traditional

\section{INTRODUCTION}

Acrocomia aculeata, native palm; also called coyol palm, it is distributed from Mexico to Costa Rica (NOTIMEX, 2011). Particularly in Mexico, this palm is found along the coastal plains of the Gulf of Mexico and the Pacific; in Chiapas it is located especially in the region of La Frailesca, Centro and Soconusco (Zuart-Macías et al., 2013). It is a palm of rapid reproduction, the same that is observed in pastures and savannas (NOTIMEX, 2011; Mondragón, 2015); adapted to habitat with disturbances, it reaches $15-20 \mathrm{~m}$ in height. The importance of this palm (A. aculeata), lies in the diversity of uses by the regional population; among which its medicinal properties stand out, as well as artisanal (Zuart-Macías et al., 2013), the use of the fruits, which are consumed in the form of a preserve known as "dulce de coyol” (Díaz Montesinos et al., 2011; Ramírez Hernández et al., 2013; Farrera et al., 2020) and the flowers; which are also edible. The taberna is a drink product of the fermentation of the sap obtained from the trunk of the palm and is produced in different countries, 
from Mexico to Central America (Payas, Honduras, where it is known by the name of sap wine; Guanacaste) (Lentz, 1990). In Mexico, the extraction and consumption of this drink is of utmost importance among the populations that produce, becoming even in some ejidos of the Isthmus of Tehuantepec, one of the main traditions that are carried out in different festivities (Mondragón, 2015). In Chiapas the taberna is consumed in a large part of the communities of the "Sierra Madre." Traditionally, in some regions of Chiapas known as La Concordia, Cintalapa, Villaflores and Villa Corzo, the inhabitants are accustomed to consume a large amount of taberna during Holy Week, as well as preferably in the months of february to may (NOTIMEX, 2011). Despite the importance of this resource, A. aculeata is a species little studied from the perspective of its management and conservation; in Chiapas, Toledo Espinoza (2014); with the purpose of generating basic information for its conservation, it carried out a micropropagation study through embryos and organogenesis from seedlings, as well as an analysis of landscape genetics, finding that $100 \%$ of the somatic embryos extracted from the Municipality of Villaflores germinated successfully; while only 22 and $24 \%$ of those extracted from El Ocote and La Sepultura, respectively, did so. Likewise, encouraging results were obtained regarding the use of growth regulators for organogenesis and the results of the population genetics analysis showed that there is a significant differentiation between the physiographic regions of the state. The objective of this work was to know the management that the taberna producers give to the coyol palm, in the studied communities,

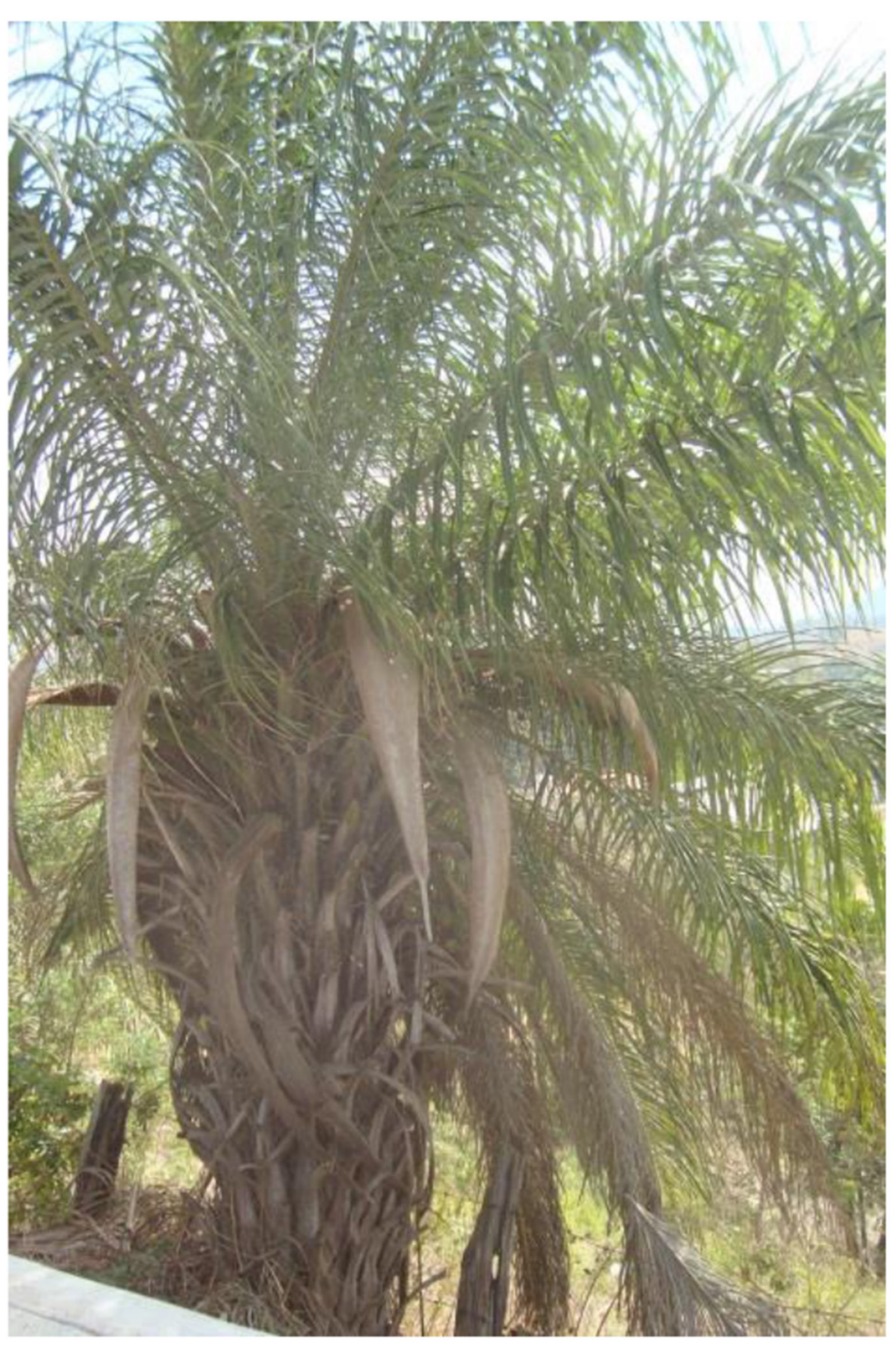

FIGURE 1 | Acrocomia aculeata in field, ready for cutting for taberna production. 
to contribute in the near future; with a management and conservation plan for the species, which guarantees the resource to the communities and helps preserve the biological and cultural diversity associated with this activity, highlighting relationship between natural resources, people, regions and local culture.
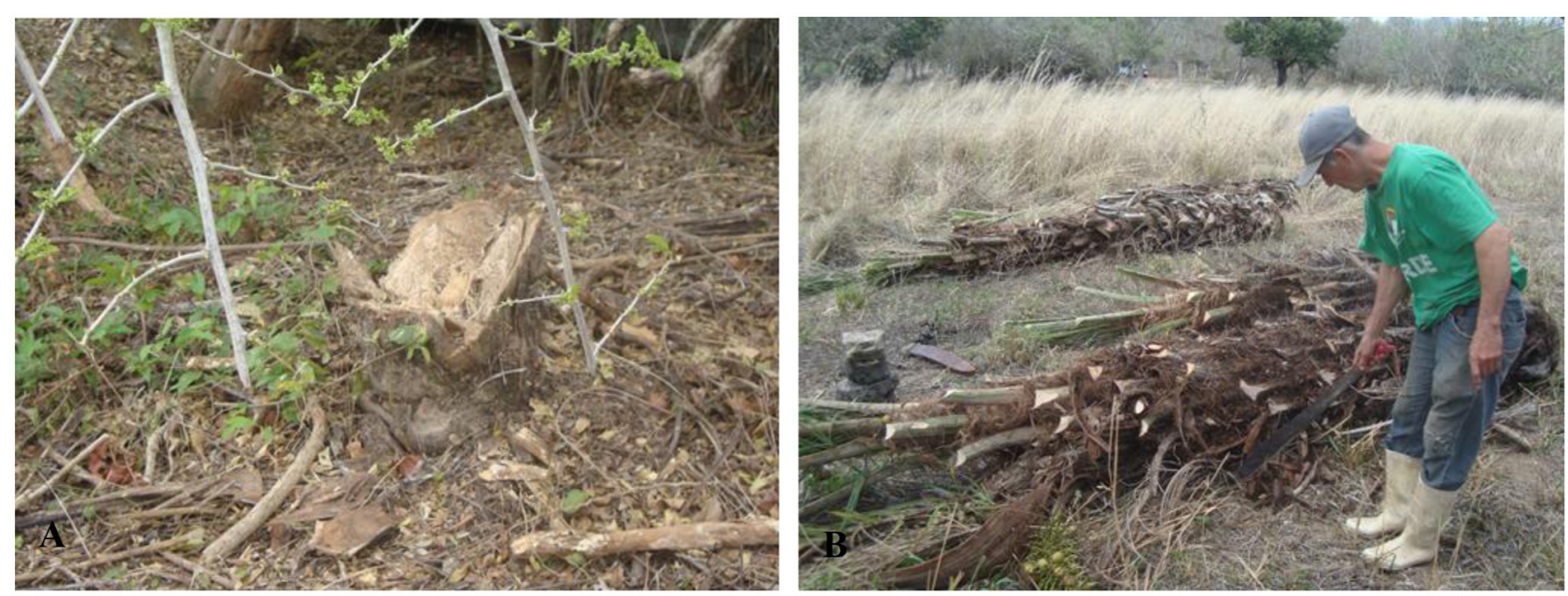

FIGURE 2 | Cutting of Acrocomia aculeata in the field. Appearance of trunk cut (A), removal of foliage in preparation for taberna production (B).

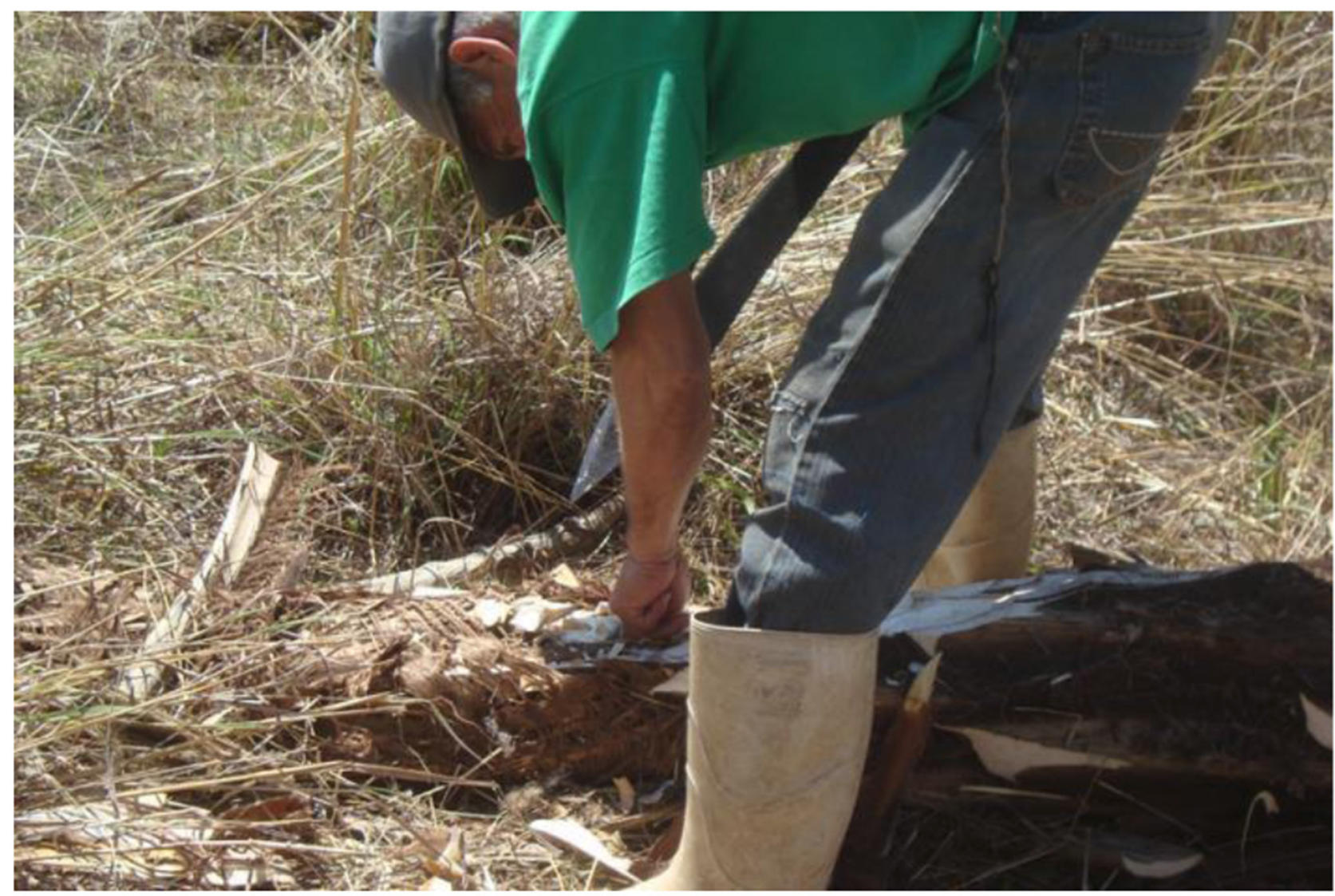

FIGURE 3 | Cutting of the palm trunk, for the formation of the "canoe," from which the taberna will be obtained. 


\section{MATERIALS AND METHODS}

The present work consisted of a case study carried out in two localities of the state of Chiapas [ejido Tierra y Libertad (TyL), municipality of Jiquipilas and Benito Juárez (BJ), municipality of Villaflores]. During the months of march and april 2016.

Firstly, authorization for access to the community was requested with the Ejidal Commissariat, who was asked to request the approval of the ejidatarios in general in order to conduct the research.

Once approval was obtained, we proceeded to identify the families in charge of the production of the taberna, who, through semi-structured interviews, were asked to describe and demonstrate in a practical way, the production process of the beverage, from the selection of the palm, the cutting and preparation of the plant, to the production of the Taberna.

\section{RESULTS}

Once permission was obtained from the authority of each locality, two taberna producing families were identified, one in each community, who reported that the taberna's production process has been transmitted orally from generation to generation. According to the information obtained, in both communities, traditionally the taberna was consumed and produced by different inhabitants, however, at present this activity is only carried out by some people, who we can consider as specialists; also called "Maestros Taberneros." In the case of Benito Juárez, there are two maestros taberneros, over 60 years old and in Tierra y Libertad, only one. The interviewees reported that the taberna is consumed during the Easter season, which coincides with the season of the year when the temperature is high (hot weather), in this way, the producers have observed that the sap is prevented from having a sticky consistency. The age of the palm should range between 5 and 15 years of age; it is important to mention that the longer the palm is, the taberna production will take place for a longer time (about 2 months). The specialists reported that the palms are obtained directly from the field, that sometimes they are developed on their farms and they use them freely to make the drink, however, when they do not have them available in this way, they can buy them from other inhabitants who do have them on their lands, and acquire them at a cost of up to $\$ 300.00$ pesos. The taberna production process is detailed as described by the producers as follows:

Cutting and cleaning process: It consists of choosing the palms of considerable age for the production of the tavern, the trees that are more than $5 \mathrm{~m}$ high are used to obtain the taberna (Figure 1). Once chosen, the palm is cut from the base of the trunk (Figure 2A), on the ground it is cleaned trying to remove from it as many thorns and leaves (Figure 2B), leaving the trunk clean. In the town of Benito Juárez, the producer transports the palms to his backyard, which is where the taberna-making process continues, while in the town of Tierra y Libertad, the producer leaves the palms in the place where they were cut, which is located on his property and goes to the place every day to collect the sap.

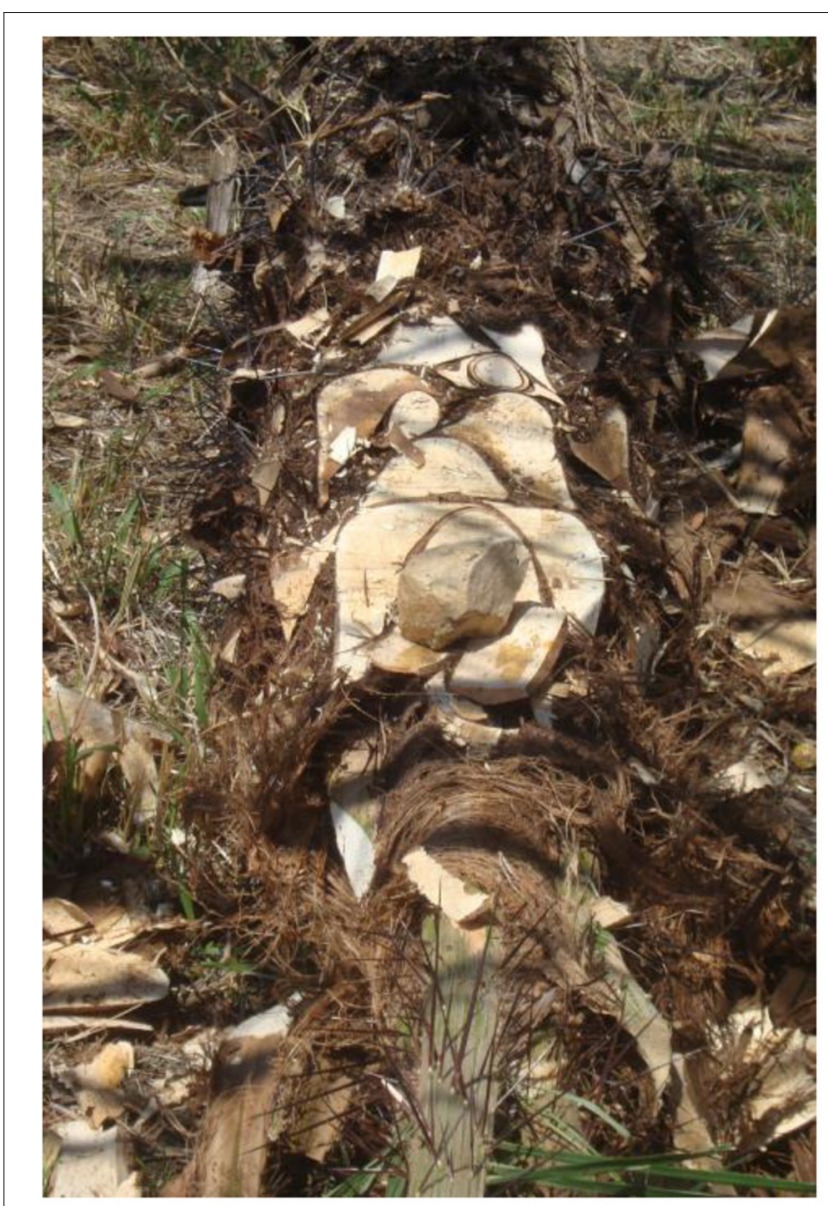

FIGURE 4 | Coyol palms once the "canoe" has been excavated and covered with a piece of wood, fastened with a stone.

Opening of the canoe: $24 \mathrm{~h}$ after cutting, the farmer makes a hole called a "canoe" (Figure 3), which is measured from $30 \mathrm{~cm}$ from the apex of the trunk toward the stem and the first cut is made parallel to the base of the trunk, the following cuts are perpendicular to the first cut of the width of the machete used, and a final cut to obtain a square of the stem, which is extracted to verify that the cuts were made at the height of the so-called "palmito" (medullar part of the plant); The stem is then left to rest for another $24 \mathrm{~h}$ and the process of extracting the sap and cleaning the palm continues. The "canoe" is covered with a piece of the same palm or with a piece of wood, to avoid the entry of dust or garbage on the sap, in this study; the canoe was covered with a piece of wood, held with a stone (Figure 4).

Extraction of the sap: After $24 \mathrm{~h}$, the producer is ready to extract the sap that emanates from the trunk, with the help of a plastic hose; he sucks the liquid and deposits it in a jug or plastic bottle, collecting around 2 to $3 \mathrm{~L}$ of taberna every $12 \mathrm{~h}$; of each palm (Figure 5). The drink is transferred to a plastic container, where it is stored for sale and/or consumption by the family. At the beginning of the process, the drink has a sweet taste and with the passage of days it acquires an alcoholic flavor, so the producer 


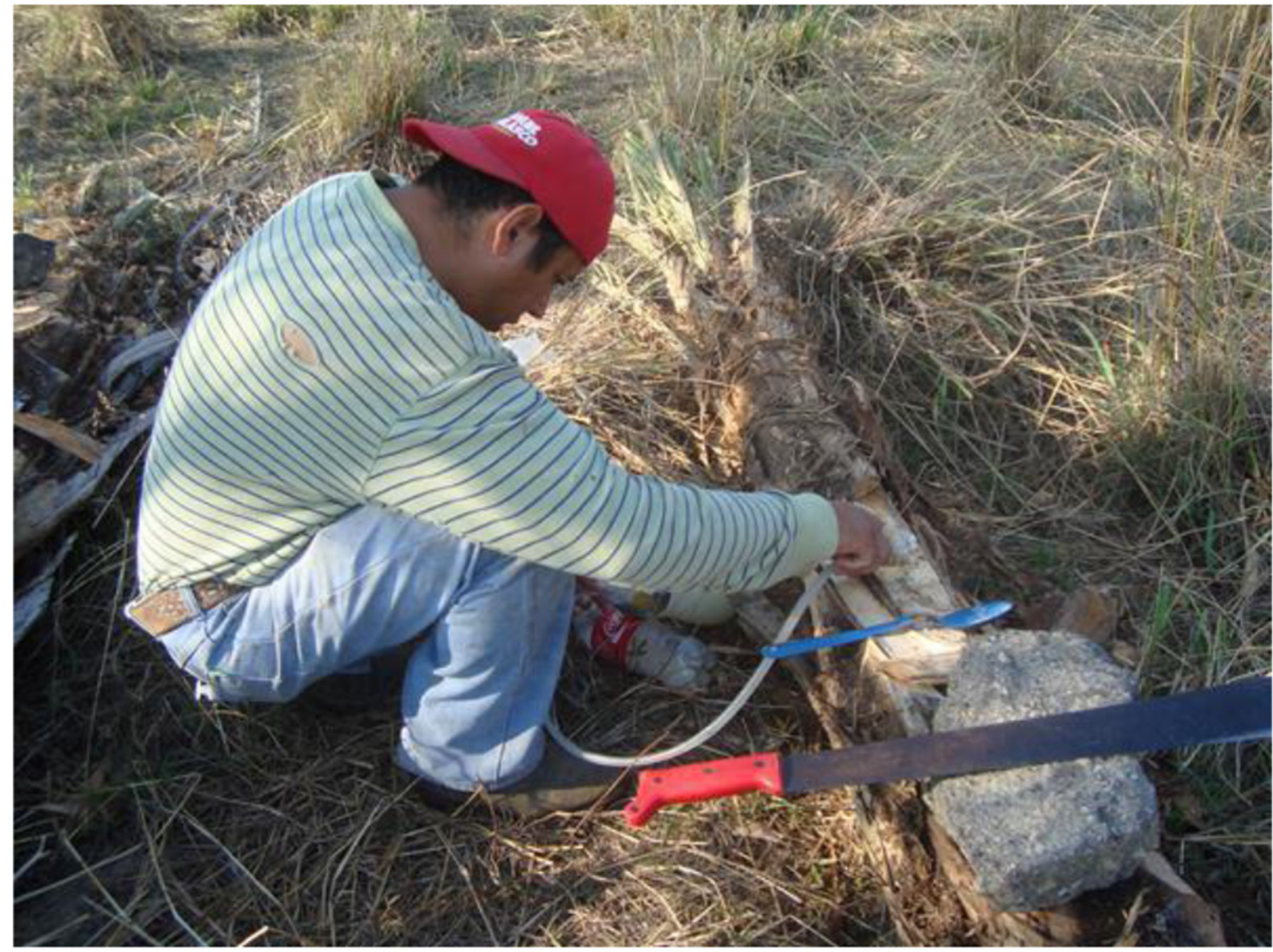

FIGURE 5 | Extraction of the sap accumulated in the palm "canoe," using a plastic hose.

must leave the container between open to avoid excess gases and its explosion.

Scraping and cleaning of the canoe: After extracting the sap, the canoe is scraped and cleaned, which consists of scraping the walls of the canoe in its four cardinal points with the help of a machete previously cleaned with water; in this way, the scraping consists of cutting between one centimeter each side of the canoe, trying not to leave residues of the trunk or the heart of palm inside the hole, which is then washed with water and cleaned with a previously washed spoon (Figure 6). The extraction of the sap, as well as the scraping and cleaning of the canoe, is done every $12 \mathrm{~h}$ (between six in the morning and six in the afternoon; during 15-30 days) during the season of taberna production.

Marketing, beliefs and traditions: The two producers who collaborated in this study refer that each year, they can produce taberna of around 20 to 30 palms, so that on average, the annual production oscillates around $2,700 \mathrm{~L}$ per year, considering the first 15 days of production, since from that time on, the flow of sap is less and the taberna production gradually decreases. The sugar content is also lower, after this time; which impacts the taste of the drink, making it less attractive to consumers, although producers report that in some years, production can extend up to a month. The taberna is sold at a price of $\$ 25.00$ per liter; marketing is done directly by the producer to consumers or distributed informally to people who transport it to other locations where it is also customary to consume the drink in the Easter season. In this case study, the interviewees described some bodily effects of consuming it, mainly the weakening of the legs. The interviewees stated that the consumption of the taberna in addition to being part of recreational and ceremonial activities, they also do it for health reasons, mentioning that the drink can be used to alleviate gastrointestinal diseases, they also pointed out the custom of taking the drink directly from the palm using a reed to inhale it, another custom among the consumers of the taberna; is to take it in the form of "bolis" (the frozen drink inside a small plastic bag), or served in glasses adding ice, water and table sugar and drinking it as a soft drink, this practice is done after the sap has been kept preserved bulk in the plastic containers, that is, not from the freshly extracted palm sap. Likewise, they indicated that they have the custom of decorating the stems that are being 


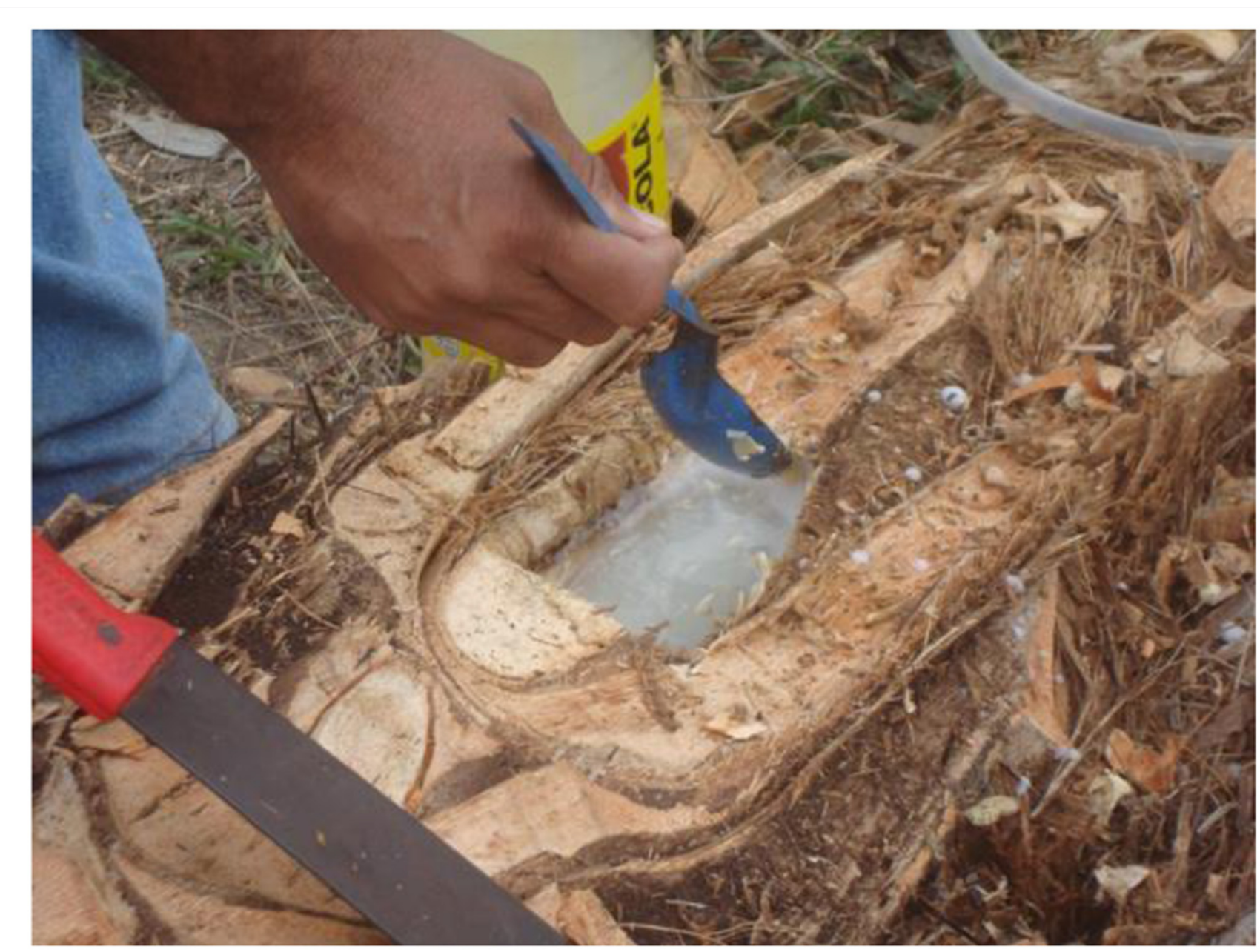

FIGURE 6 | Scraping and cleaning process of the "canoe" after as much sap as possible was extracted.

used for taberna production with red ribbons, to avoid the "mal de ojo," caused by people with "strong eyes" and that decompose the drink.

\section{DISCUSSION}

The information provided by the families of the producers in the communities under study coincides with data on the use of the palm in other localities, as mentioned by different authors (Díaz Montesinos et al., 2011; Ramírez Hernández et al., 2013; ZuartMacías et al., 2013; Farrera et al., 2020), who describe A. aculeata as a multipurpose species used by the inhabitants of the Frailesca region, in these reports they mention that they use the fruits and flowers as food and for their medicinal properties, as well as for the preparation of beverages. Other authors also report the use of flowers in a ceremonial way in some localities of Chiapas (Bermúdez, 2011). The season of production and consumption of taberna during Holy Week is the same as in some ejidos of the Isthmus of Tehuantepec, in one of the main traditions carried out in different festivities (Mondragón, 2015). Prior to this study, the elaboration of taberna has been reported, using $A$. aculeata as raw material in the Maya Frailesca region (AlcántaraHernández et al., 2010; Santiago-Urbina et al., 2013; Coutiño et al., 2020), where the municipalities under study belong. The sap is fermented naturally, without the producers adding any inoculum, carrying out acidic, alcoholic and sometimes acetic fermentations, which gives the drink its characteristic flavor. The sweet taste of the sap produced in the 1st days of collection is due to the presence of sucrose and other sugars, as indicated by Luján-Hidalgo et al. (2019), who reported a concentration of $110 \mathrm{~g} / \mathrm{L}$ of sucrose, as well as 48 and $51 \mathrm{~g} / \mathrm{L}$ of glucose and fructose; respectively, and its decrease with the passing of the days explains the change of flavor to one of alcoholic taste, due to the fact that these sugars are used by the developed native microbiota; transforming them into a mixture of compounds, among which are mainly ethanol, whose concentration can reach $4.7-10.31 \% \mathrm{w} / \mathrm{v}$, depending on the environmental conditions and the time of collection of the drink (Santiago-Urbina et al., 2013; Coutiño et al., 2015, 2020). Regarding the use of the taberna as 
a remedy for some gastrointestinal diseases; Romero-Luna et al. (2017) pointed out that the taberna, among other traditional drinks, contain beneficial microorganisms for health, since they improve the balance of the intestinal flora, thereby reducing the risk of gastrointestinal diseases. In studies carried out in taberna, an autochthonous microbiota composed of lactic and acetic bacteria and yeasts has been found (Alcántara- Hernández et al., 2010; Santiago-Urbina et al., 2013, 2015; Luján-Hidalgo et al., 2019), which possibly confer probiotic potential to the beverage, as pointed out by Coutiño et al. (2020), who also point out that the taberna contains bioactive compounds, such as phenolic compounds, vitamins, short-chain fatty acids, among others; that can be generated by the microbiota developed during the fermentation of the sap, or come directly from the plant. Regarding the custom of attaching a red ribbon to the stems, Zuart-Macías et al. (2013) also describe this practice, to avoid excessive and sudden acidification of the taberna, caused by the admiration of people who are not familiar with it, even commenting that some producers prevent the passage of strangers to the place where the stems of the palms in production are located.

\section{CONCLUSIONS}

The production of taberna is a predominantly family economic activity among the inhabitants of the communities of the Frailesca Region of the State of Chiapas, which has been transmitted from generation to generation, and is surrounded by myths and beliefs among them. Until a few years ago, the plant was used directly from the field, but in recent years, it has begun to be cultivated to use it, but those who use it for taberna production are people with around 60 years of age. The use of the palm to make taberna reflects a cultural aspect of the central depression of Chiapas. The growing interest in disseminating the uses of traditional fermented beverages can contribute to the generation of an adequate management plan for A. aculeata, to ensure that this activity lasts and the tradition is preserved, also taking advantage of the biotechnological potential of the taberna as a probiotic. The article contributes to continue documenting

\section{REFERENCES}

Alcántara- Hernández, R. J., Rodríguez- Álvarez, J. A., Valenzuela- Encinas, C., Gutiérrez- Miceli, F. A., Castañón- González, H., Marsh, R., et al. (2010). The bacterial Community en 'taberna'a traditional beverage os Southern México. Lett. Appl. Microbiol. 51, 558-563. doi: 10.1111/j.1472-765X.2010.02 934.x

Bermúdez, H. I. D. (2011). Elaboración in vitro de una bebbida tipo "taberna". México: Instituto Tecnológico de Tuxtla Gutiérrez.

Coutiño, B., Flores, A. C., Vela-Gutiérrez, G., Sepúlveda, L., Aguilar, C. N., ChavezGonzalez, M., et al. (2020). Tavern or coyol wine: a beverage from palm sap with biotechnological potential. Biotechnol. Prog. Beverage Consumpt. 19, 233-252. doi: 10.1016/B978-0-12-816678-9.00007-2

Coutiño, B., Rodríguez, R., Belmares, R., Aguilar, C., and Ruelas, X. (2015). Selección de la bebida "taberna" obtenida de la palma Acrocomia aculeata y análisis químico proximal. Multiciencias 15:4.

Díaz Montesinos, M. G., Farrera Sarmiento, O., and Isidro Vázquez, M. A. (2011). Estudio etnobotánico de los principales mercados de Tuxtla Gutiérrez, Chiapas, México. Lacandonia. 5, 21-42. the elaboration of this drink and begins its use in a context of resource management, because its cultivation for these purposes is already beginning to be a valued drink, locally and regionally, it is important to preserve local knowledge for its elaboration. The use of natural resources, finally, is a biocultural heritage that implies a relationship between natural resources, people, regions and local culture.

\section{DATA AVAILABILITY STATEMENT}

The raw data supporting the conclusions of this article will be made available by the authors, without undue reservation.

\section{ETHICS STATEMENT}

The studies involving human participants were reviewed and approved by the Ejidal Commissariat, who requested the approval of the ejidatarios to conduct the research. The participants provided their informed consent to participate in this study.

\section{AUTHOR CONTRIBUTIONS}

JA-R conducted fieldwork and contributed to the writing of the manuscript. AV-V, CO-G, and MS-C contributed to conception and design of the study and contributed to manuscript revision, read, and approved the submitted version. All authors contributed to the article and approved the submitted version.

\section{FUNDING}

The work was funded partially by a grant from Consejo Nacional de Ciencia y Tecnología (CONACYT) to JA-R.

\section{ACKNOWLEDGMENTS}

The authors thank the taberna-producing families for the information provided. 
Importancia agroecológica del coyul (Acrocomia mexicana Karw. ex Mart.). Estudios Sociales. Rev. Alimentación Contemp. Desarrollo Reg. 21, 97-113.

Romero-Luna, H. E., Hernández-Sánchez, H., Dávila-Ortíz, G. (2017). Traditional fermented beverages from México as a potential probiotic source. Ann Microbiol. doi: 10.1007/s13213-017-1290-2

Santiago-Urbina, J. A., Arias-García, J. A., and Ruíz-Terán, F. (2015). Yeast species associated with spontaneous fermentation of taberna, a traditional palm wine from the southeast of Mexico. Ann Microbiol. 65, 287-296. doi: $10.1007 / \mathrm{s} 13213-014-0861-8$

Santiago-Urbina, J. A., Verdugo-Valdez, A. G., and Ruiz-Terán, F. (2013). Physicochemical and microbiological changes during tapping of palm sap to produce an alcoholic beverage called "taberna", which is produced in the south east of Mexico. Food Control 33, 58-62. doi: 10.1016/j.foodcont.2013. 02.010

Toledo Espinoza, X. E. (2014). Micropropagación y genética del paisaje de Acrocomia aculeata (Jacq. Lodd. ex Mart) en chiapas, conocimiento para su manejo. Universidad de Ciencias y Artes de Chiapas. Maestría en Ciencias Biológicas. Chiapas: Tuxtla Gutiérrez.

Zuart-Macías, J. L., Ponce-Díaz, P., and Santiago-Marroquín, G. (2013). "Palma de coyol (Acrocomia mexicana Karw. Ex Mart.)," in La biodiversidad en Chiapas:
Estudio de Estado. México: Comisión Nacional para el Conocimiento y Uso de la Biodiversidad/Gobierno del Estado de Chiapas.

Conflict of Interest: The authors declare that the research was conducted in the absence of any commercial or financial relationships that could be construed as a potential conflict of interest.

Publisher's Note: All claims expressed in this article are solely those of the authors and do not necessarily represent those of their affiliated organizations, or those of the publisher, the editors and the reviewers. Any product that may be evaluated in this article, or claim that may be made by its manufacturer, is not guaranteed or endorsed by the publisher.

Copyright $\odot 2021$ Ambrocio-Ríos, Orantes-García, Sánchez-Cortés and VerdugoValdez. This is an open-access article distributed under the terms of the Creative Commons Attribution License (CC BY). The use, distribution or reproduction in other forums is permitted, provided the original author(s) and the copyright owner(s) are credited and that the original publication in this journal is cited, in accordance with accepted academic practice. No use, distribution or reproduction is permitted which does not comply with these terms. 